\title{
Association of Serum Magnesium Levels with Matrix metalloproteinase-9 Urine in Patients with Diabetic Kidney Disease Stage 1 and 2
}

\author{
M. Hashemi Rafsanjani ${ }^{1}$, Sony Wibisono Mudjanarko ${ }^{2 *}$, Chandra Irwanadi ${ }^{3}$ \\ ${ }^{1}$ Faculty of Medicine, Universitas Airlangga, Surabaya, Indonesia \\ ${ }^{2}$ Endocrinology and Metabolism Division, Department of Internal Medicine, Faculty of Medicine, Universitas Airlangga - \\ Dr. Soetomo General Hospital Surabaya, Indonesia \\ ${ }^{3}$ Nephrology and Hypertension Division, Department of Internal Medicine Faculty of Medicine, Universitas Airlangga - Dr. \\ Soetomo General Hospital Surabaya, Indonesia
}

\section{A R T I C L E I N F O}

\section{Article history:}

Received 29 August 2019

Received in revised form 11

October 2019

Accepted 25 October 2019

Available online 31 October 2019

Keywords:

Serum Magnesium Levels, MMP-9,

Diabetic Kidney Disease, DKD.

*) Corresponding author: sonywibisono@yahoo.com

\begin{abstract}
A B S T R A C T
Introduction: The progressiveness of stage 1 and 2 kidney disease is indicated by an increase in matrix metalloproteinase-9 (MMP-9). Development of diabetic kidney disease (DKD) is characterized by a thuckening of the glomerular basement membrane followed ultimately by progression to glomerular sclerosis and fibrosis. One of the factors that contribute is magnesium levels. We aim to determine the association between serum magnesium levels and MMP-9 urine in patients with stage 1 and 2 DKD.

Methods: The cross sectional study from stage 1 and 2 DKD patients. Patients were examined for serum magnesium levels and urine MMP-9. Urine MMP-9 examination was taken from the middle portion urine collection and examined using Sandwich-ELISA method then normalized with urine creatinine. The correlation between magnesium and MMP-9 urine was analyzed by the Spearman rank test.

Results: This study involved 56 subjects. The mean serum magnesium level is $1.8 \pm 0.26 \mathrm{mg} / \mathrm{dl}$. The mean MMP-9 is $120 \mathrm{ng} / \mathrm{g}$ creatinin. The mean value of FBS (fasting blood sugar) in patients in the study was $153.29 \pm 50.22 \mathrm{mg} / \mathrm{dL}$. The mean value PPBS (post prandial blood sugar) was $233.61 \pm 71.3 \mathrm{mg} / \mathrm{dL}$. The mean HbA1c value was $7.6 \pm 1.13 \%$. The mean creatinin serum value was $1.1 \pm 0.43 \mathrm{mg} / \mathrm{dL}$. There is a significant negative relationship with a moderate correlation between serum magnesium levels and urine MMP-9 ( $\mathrm{p}=0.000, \mathrm{r}-0.512)$.

Conclusion: There is a significant negative relationship between serum magnesium levels and urine MMP-9 in stage 1 and 2 DKD patients.
\end{abstract}

\section{Introduction}

One complication of diabetes mellitus that needs attention is diabetic kidney disease (DKD). DKD has a major contribution to the high cost of care, decreased quality of life, and mortality from DKD to the end stage renal disease. ${ }^{1}$ Early stage 1 and 2 DKD if not getting the right management will progress to the end stage renal disease which will eventually require kidney replacement therapy or lifelong dialysis. Several factors influence the progression of DKD. One factor that contributes to the progression of stage 1 and $2 \mathrm{DKD}$ is magnesium levels. ${ }^{2,3}$

Stage 1 and 2 DKD characterized by hyperglycemia causes decreased magnesium reabsorption in the proximal tubule thereby increasing the amount of urinary magnesium excretion in the kidneys and causing hypomagnesemia. This hypomagnesemia causes hemodynamic changes, the occurrence of inflammatory processes, and endothelial dysfunction that affects the progression of diabetes in kidney disease for the occurrence of an end stage renal disease., ${ }^{4,5}, 6$ This hemodynamic change in hypomagnesemia increases the RAAS (renin-angiotensin-aldosteron system) that will produce angiotensin II so that efferent vasoconstriction occurs which ultimately results in glomerulosclerosis and fibrosis. The progression of kidney disease is indicated by an increase in matrix metalloproteinase-9 (MMP-9) in stages 1 and 2. Increased MMP-9 plays a role in the progression of renal fibrosis and is mainly secreted in the glomerulus, and is also found in the tubulointerstisium. ${ }^{7,8}$

Matrix metalloproteinase-9 (MMP-9) is a proteolytic enzyme that degrades extracellular matrix (ECM) components consisting of gelatin, type IV collagen, and laminin. When the kidneys get injured, for example by 
the process of hyperglycemia, the series of processes that occur will cause an increase in transforming growth factor- $\beta$ (TGF- $\beta$ ). Increasing TGF- $\beta$ will produce more ECM. On the other hand, increased TGF- $\beta$ will also increase MMP-9. Increased MMP-9 secretion is evident when the number of nephrons is sufficient at stages 1 and 2 . This increase can be detected through serum or urine. The next process MMP9 will increase remodeling which causes tissue imbalance resulting in an accumulation of ECM deposition. ${ }^{8}$ Research that studies the relationship between serum magnesium levels and MMP-9 has not been widely known. Considering the role of magnesium in the progressivity of DKD, we aim to examine the relationship between magnesium serum and MMP-9 urine in patients with DKD stage 1 and 2.

\section{Methods}

This was an analytic observational study with crosssectional design. the study was conducted at Tertiary General Hospital in Surabaya. The study was conducted during the period of September to December 2018. The population study was all patients with stage 1 and 2 DKD who seek treatment at the Endocrinology Metabolic and Diabetes outpatient clinic. The subjects were taken by consecutive sampling.

The inclusion criteria for this study were diagnosed DKD stage 1 and 2 based on eGFR which uses the Cockroft-Goult formula and is characterized by microalbuminuria, aged age more than 20 years, HbA1c $\geq 6.5$ and subject agreed to participate in the study. Exclusion criteria for case and control groups were patients who had gastrointestinal disease, chronic diarrhea, hypertension, pregnant and lactating women, proton pump inhibitor user, history of alcohol, medicine containing magnesium consumption, urinary tract infections. This study met the ethical clearance by Ethical Committee in Health Research Dr. Soetomo General Hospital Surabaya and informed consent was obtained from each subject of the study.

All subjects underwent the same examination and assessment. Physical examination and laboratorium data were collected. All subjects will be subjected to venous blood sampling according to the procedure to determine serum magnesium levels and then record and analyze data. Urine samples were obtained from the subjects immediately after enrollment.

\section{Sample Collection}

Taking blood serum as much as $3 \mathrm{cc}$ with Li-Heparin anticoagulant, turning back slowly until homogeneous and then let stand for 30-45 minutes until the blood is frozen and then in the centrifuge $1000 \mathrm{~g}$ (around 3000 rpm) for 15 minutes then the serum is immediately separated.

\section{Serum Magnesium Level}

Blood samples are then processed with a Roche Cobas C 311/501 analyzer with Magnesium Gen.2 (MG-2: ACN 70), TRIS a / 6-aminocaproic acid buffer and xylidyl blue reagents (Roche, USA) through the calorimetric method. Normal serum magnesium levels were 1.7-2.4 $\mathrm{mg} / \mathrm{dL}$.

MMP-9 Urine

The MMP-9 level examination was taken from the middle portion of urine taken during control in clinic which was then examined by the SandwichELISA method. The ELISA micro plate provided in the kit has been pre-coated with special antibodies for human MMP-9 (Quantikine cat: DMP900) following manufacture procedure. Optical density (OD) can be measured by spectrophotometry at a wavelength of 450 $\mathrm{nm} \pm 2 \mathrm{~nm}$. The detected concentration range of urine metalloproteinase-9 (MMP-9) urine was 0.313-20 ng / $\mathrm{ml}$.

\section{Statistical Analysis}

All collected data are expressed as mean value \pm SD and processed statistically using IBM SPSS Statistics for Windows, Version 25.0 (Armonk, NY: IBM Corp.). Normality data was analyzed by Kolmogorov Smirnov test. The correlation between serum magnesium levels and MMP-9 was analyzed using Pearson correlation test (when the data was normally distributed) or Spearman correlation test (when the data was abnormally distributed) for confirmation. $\mathrm{p}<0.05$ was considered significant $(95 \% \mathrm{CI})$. The strength of the relationship was based on the correlation coefficient.

\section{Results}

The subjects of this study were 19 males and 37 females of DKD stage 1 and 2 patients at Dr. Soetomo Surabaya General Hospital Outpatient Installation whom match the inclusion criterias. The study subjects had a mean age of $56 \pm 10.5$ years with the youngest age of 40 years and the oldest age of 86 years.

The nutritional status of the subjects based on Body Mass Index (BMI) had a mean and standard deviation of $24.98 \mathrm{~kg} / \mathrm{m} 2 \pm 3.14 \mathrm{~kg} / \mathrm{m} 2$. Mean systolic blood pressure of $121.55 \pm 4.3 \mathrm{mmHg}$. Mean diastolic blood pressure of $78.04 \pm 4.48 \mathrm{mmHg}$. History of diabetes counts for at least 6 months and a maximum of 34 years with an average length of disease of $7.7 \pm 6.6$ years. Data on the basic characteristics of the research subjects was shown in Table 1.

The clinical profile of the patient with a mean FBS (fasting blood sugar) of $153.29 \pm 50.22 \mathrm{mg} / \mathrm{dL}$. The mean value of PPBS in patients in the study of $233.61 \pm 71.3 \mathrm{mg} / \mathrm{dL}$. The mean HbAlc value is $7.6 \%$. The mean value of serum creatinine (SC) was $1.1 \mathrm{mg}$ / dl. The mean value of eGFR in 56 patients of study subjects was $75.89 \pm 17.1 \mathrm{ml} / \mathrm{min} / 1.73 \mathrm{~m} 2$. (Table 2). Serum Magnesium levels, MMP-9 Urine, Correlation between variables

All subjects were examined for serum magnesium levels. The results of the serum magnesium examination results of the study subjects had mean serum magnesium level was $1.8 \pm 0.26 \mathrm{mg} / \mathrm{dl}$. The highest level was $2.3 \mathrm{mg} / \mathrm{dl}$ while the lowest levels was $1.4 \mathrm{mg} / \mathrm{dl}$, hypomagnesemia patients $(<1.7 \mathrm{mg} / \mathrm{dl})$ were found in 18 patients $(32.14 \%)$.

All subjects were examined for urine MMP-9 levels. The results of the MMP-9 examination results of the study subjects had a mean of $116,84 \pm 23.8 \mathrm{ng} / \mathrm{g}$ creat. The highest level was $163 \mathrm{ng} / \mathrm{g}$ creat. while the lowest levels was $75 \mathrm{ng} / \mathrm{g}$ creat.

Spearman correlation test results obtained $\mathrm{p}=0.000$ 
and the correlation coefficient $(r)$ of -0.512 , it can be concluded that there is a significant relationship between serum magnesium levels and MMP-9 urine $(\mathrm{p}<0.05)$ with moderate relationship strength and the direction of the negative relationship, namely the higher the serum magnesium level, the higher the MMP-9 levels.

Table 1. Demographic data of research subjects

\begin{tabular}{|c|c|c|c|c|c|}
\hline Characteristics & $\mathrm{n}$ & $\%$ & $\begin{array}{c}\text { Range } \\
\text { (Min-Max) }\end{array}$ & Median & Mean \\
\hline \multicolumn{6}{|l|}{ Sex } \\
\hline Male & 19 & 33.9 & & & \\
\hline Female & 37 & 66.1 & & & \\
\hline Age & 56 & & $40-86$ & 55 & $\begin{array}{l}56.89 \pm \\
10.536 \\
\end{array}$ \\
\hline $\mathrm{BMI}\left(\mathrm{kg} / \mathrm{m}^{2}\right)$ & 56 & & $18.59-31.43$ & 25.08 & $24.98 \pm 3.14$ \\
\hline $\begin{array}{l}\text { 10Systolic BP } \\
\text { (mmHg) }\end{array}$ & 56 & & $105-133$ & 120 & $121.55 \pm 4.32$ \\
\hline $\begin{array}{l}\text { Diastolic BP } \\
(\mathrm{mmHg})\end{array}$ & 56 & & $65-88$ & 79 & $78.04 \pm 4.48$ \\
\hline $\begin{array}{l}\text { DMT2 } \\
\text { d u rat i o n } \\
\text { (years) }\end{array}$ & 56 & & $0.5-34$ & 6 & $7.7 \pm 6.6$ \\
\hline
\end{tabular}

Table 2. Clinical presentation of research subject

\begin{tabular}{lllll}
\hline \multicolumn{1}{c}{ Variable } & $\mathrm{n}$ & \multicolumn{1}{c}{ Range } & \multicolumn{1}{c}{ Median } & \multicolumn{1}{c}{ Mean } \\
\hline FBS $(\mathrm{mg} / \mathrm{dl})$ & 56 & $72-267$ & 141.5 & $153.29 \pm 50.22$ \\
\hline PPBS $(\mathrm{mg} / \mathrm{dl})$ & 56 & $125-430$ & 228.5 & $233.61 \pm 71.3$ \\
\hline HbA1c $(\%)$ & 56 & $6,6-10,1$ & 7.2 & $7.6 \pm 1.13$ \\
\hline BUN $(\mathrm{mg} / \mathrm{dl})$ & 56 & $6-55$ & 13 & $16.27 \pm 10.07$ \\
\hline S-Cr $(\mathrm{mg} / \mathrm{dl})$ & 56 & $0,54-2,18$ & 0.98 & $1.1 \pm 0.42$ \\
\hline eGFR & 56 & $60,01-134,9$ & 69.09 & $75.89 \pm 17.1$ \\
(ml/mnt/1.73m2) & & & & \\
\hline HDL (mg/dl) & 56 & $22-79$ & 45 & $47.3 \pm 11.3$ \\
\hline LDL (mg/dl) & 56 & $53-266$ & 125 & $130.38 \pm 40.7$ \\
\hline TG (mg/dl) & 56 & $68-371$ & 138.5 & $155.73 \pm 70.39$ \\
\hline Total chol.(mg/dl) & 56 & $106-367$ & 187 & $195.46 \pm 48.9$ \\
\hline MicroAlb (mg/g) & 56 & $31-297$ & 108 & $132.64 \pm 87.84$ \\
\hline
\end{tabular}

Table 3. Profile of serum magnesium levels in study subjects

\begin{tabular}{lccccc}
\hline \multicolumn{1}{c}{ Variable } & $\mathrm{n}$ & $\%$ & Range & Median & Mean \\
\hline $\begin{array}{l}\mathrm{Mg} \text { serum } \\
(\mathrm{mg} / \mathrm{dl})\end{array}$ & 56 & 100 & $1.4-2.3$ & 1.8 & $1.8 \pm 0.26$ \\
\hline$<1,7$ & 18 & $32.14 \%$ & & & \\
\hline $1,7-2,3$ & 38 & $67.86 \%$ & & & \\
\hline
\end{tabular}

Table 4. The results of examination of MMP-9 values of research subjects

\begin{tabular}{|c|c|c|c|c|c|}
\hline Variable & $\mathrm{n}$ & $\%$ & Range & Median & Mean \\
\hline $\begin{array}{l}\text { MMP - } \\
9 \quad(\mathrm{ng} / \mathrm{g} \\
\text { kreat) }\end{array}$ & 56 & 100 & $75-163$ & 120 & $116.84 \pm 23.8$ \\
\hline
\end{tabular}

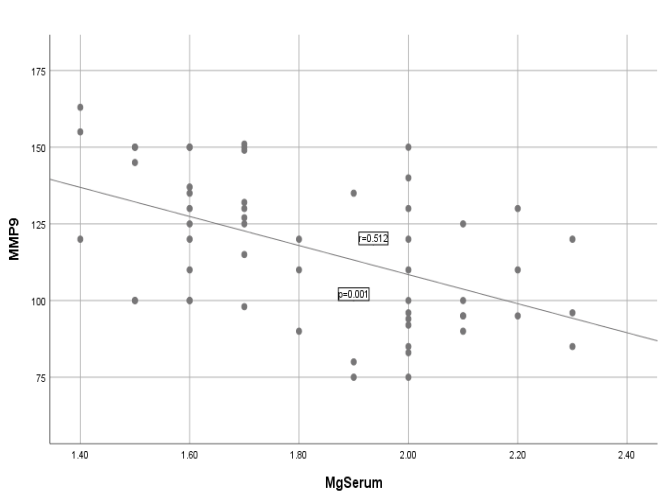

Figure 1. Correlation between serum magnesium level and MMP-9 urine of research subjects.

\section{Discussion}

This current study suggests that one of the factors that contribute to the progression of stage 1 and 2 DKD is magnesium levels. DKD is characterized by excessive deposition of ECM proteins in the mesangium and basement membrane of the glomerulus and in renal tubulointerstitium. The basement membrane changes, accompanied by glo $\neg$ merular hyper filtration, and increased glomerular hydrostatic pressure leading to microalbuminuria $(9,10)$. However, the mesangial changes appear to be the main cause of declin $\neg$ ing renal function in diabetic nephropathy. Declining glomerular function cor $\neg$ relates well with the extent of these changes in both types of diabetes. ${ }^{11,12}$ The major physiologic regulators of ECM degradation in the glomerulus are matrix metalloproteinases (MMPs) ${ }^{13,14}$ MMP-9 may be involved in the pathogenesis and progression of type 2 diabetic nephropathy. It appears that measurements of urinary MMP-9 may be useful for evaluating the degree of renal injuries in patients with type 2 diabetic nephropathy, especially in the early stage. Diabetic nephropathy is characterized by a profound shift in the ECM turnover toward increased matrix accumulation. Type-IV collagen is the major collagenous component of the ECM. It appears that the overproduction and the increase of urinary excretion of MMP-9, a degradation factor, may occur in the early stage of type 2 diabetic nephropathy ${ }^{15,19}$ Clinically MMP-9 can be used as a marker of kidney damage because it can detect especially at an early stage so that it is more aware and anticipated for further kidney damage. Even earlier before the occurrence of microalbuminuria. ${ }^{8.15}$ However this reagent is still quite expensive so it cannot be applied widespread in clinical.

Our study resulted magnesium levels and MMP-9 urine was a significant negative correlation $\mathrm{n}$ this study a decrease in magnesium or hypomagnesemia levels causes hemodynamic changes, triggers an inflammatory process, and endothelial dysfunction. Decreasing magnesium levels increases the RAA system which will produce angiotensin II so that efferent vasoconstriction occurs which ultimately causes glomerulosclerosis and fibrosis. Hypomagnesemia also triggers pro-inflammatory cytokines through $\mathrm{NF} \kappa \beta$ induction which can increase proinflammatory cytokines such as IL-1, IL-6, IL-18 and TNF- $\alpha$, pro-inflammatory chemokines and adhesion 
molecules that encourage infiltration of mononuclear cells from circulation to circulation. kidney. Activated ROS is associated with mesangial cell hypertrophy which increases renal fibrosis. Endothelial dysfunction can increase vascular endothelial cell hypermeability, play a role in glomerular hypersellularity and thickening of GBM (glomerular basal mebrane) which results in glomerurosclerosis and fibrosis. ${ }^{16,17}$

The progression of fibrosis in DKD is indicated by an increase in MMP-9. When the kidneys get injured by the hyperglycemia process, a series of processes that occur will cause an increase in transforming growth factor- $\beta$ (TGF- $\beta$ ) and produce a large number of ECM. ${ }^{8,19,20}$

The limitations of this study including cross-sectional design so that various types of tests such as magnesium levels and MMP-9 urine were carried out at one time. This causes researchers to be unable to evaluate changes in various parameters that fluctuate.

\section{Conclusion}

Serum magnesium levels were negative correlated with MMP-9 urine. This findings supported that in DKD there is a decrease in serum magnesium levels and in early stage DKD there is an increase in MMP-9.

\section{Conflict of Interest}

The author stated there is no conflict of interest

\section{References}

1. Diaz AG, Villasenor LP, Escatell FG, Sierra JA. Oxidative Stress in Diabetic Nephropathy with Early Chronic Kidney Disease. Journal of Diabetes Research. 2016; 1-2

2. Pham PC, Pham PM, Pham PA, Pham SV. Lower serum magnesium levels are associated with more rapid decline of renal function in patients with diabetes mellitus type 2. Clin Nephrol. 2005; 63(6): 429-36.

3. Pham PC, Pham PM, Pham PT, Pham SV. The link between lower serum magnesium and kidney function in patients with diabetes mellitus type 2 deserves a closer look. Clin Nephrol, 2009; 71(4):3759.

4. Hans CP, Sialy R\& Bansal DD. Magnesium deficiency and diabetes mellitus. Current Science, 2002; 83(12): 156-1462.
5. Hasegawa G, Nakano K, Kondo M, 2005. Role of TNF and IL-1 in the development of diabetic nephropathy. Nefrologia, 15: 1-4

6. Lim, 2014. Diabetic nephropathy - complications and treatment. International Journal of Nephrology and Renovascular Disease 7: 361-381

7. Cheng Z, Limbu M, Wang Z, Liu J, Liu L, Zhang X, 2017. MMP-2 and 9 in Chronic Kidney. Int. J. Mol. Sci.18: 776

8. Mahendran K, Sethupathy S, Perumal K, Inmozhi R, Santha K, 2015. Plasma and urinary matrix metalloproteinase- 9 as a marker for detection of nephropathy in type 2 diabetic patients. International Journal of Medical Science and Public Health 4(10):1409-1412

9. Osterby R, Gall MA, Schmitz A, Nielsen FS, Nyberg G, Parving HH: Glomerular structure and function in proteinuric type 2 (non-insulindependent) diabetic patients. Diabetologia 1993;36:1064-70.

10. Steffes MW, Osterby R, Chavers B, Mauer SM: Mesangial expansion as a central mechanism for loss of kidney function in diabetic patients. Diabetes 1989;38:1077-81

11. Osterby R, Tapia J, Nyberg G, Tencer J, Willner J, Rippe B, Torffvit O. Renal structures in type 2 diabetic patients with elevated albumin excretion rate. APMIS 2001;109:751-61.

12. Osterby R, Hartmann A, Nyengaard JR, Bangstad HJ. Development of renal structural lesions in type 1 diabetic patients with microalbuminuria. Observations by light microscopy in 8-year follow-up biopsies. Virchows Arch 2002;440:94-101

13. Woessner JF Jr. Matrix metalloproteinases and their inhibitors in connective tissue remodeling. FASEB J 1991;5:2145-54.

14. Lenz O, Elliot SJ, Stetler-Stevenson WG. Matrix metalloproteinases in renal development and disease. JASN 2000;11(3):574-81.

15. Tashiro K, Koyanagi I, Ohara I, Ito T, Saitoh A, Horikoshi S, Tomino Y, 2004. Levels of Urinary Matrix Metalloproteinase-9 (MMP-9) and Renal Injuries in Patients With Type 2 Diabetic Nephropathy. Journal of Clinical Laboratory Analysis 18:206-210

16. Azeem M, Iqbal A, Butt N, Randhawa FA, Malik U, 2017. Frequency of Type-2 diabetes mellitus in Nephropathic patients and comparison of mean magnesium levels in Nephropathic patients with and without Type-2 diabetes mellitus. Pak J Med Sci 33(5): 1254-1259

17. Bherwani S, Jibhkate SB, Saumva AS, Patel SK, Singh R, 2016. Hypomagnesemia: a modifiable risk factor of diabetic nephropathy. Hormone molecular Biology and clinical investigation 29(3):79-84.

18. Silva AP, Fragoso A, Silva C, Tavares N, Santos N, Martins H, 2014. Magnesium and Mortality in Patients with Diabetes and Early Chronic Kidney Disease. J Diabetes Metab, 5:3

19. Derosa G, Maffioli P, D’Angelo A, Salvadeo SA, Ferrari I, Fogari E, Gravina A, Mereu R, Palumbo I, Randazzo S, Cicero A. 2009. Evaluation of metalloproteinase 2 and 9 levels and their inhibitors in combined dyslipidemia. Clin Invest Med 32 (2): E124-E132.

20. Shet N, Shetty S, Rao A, 2014. To Study Serum Mmp-9 Levels In Early Diabetic Nephropathy. International Journal of Pharmaceutical Science Invention ISSN (Online): 2319 - 6718 